\title{
Alterations in Platelet Function and Cell-Derived Microvesicles in Recently Menopausal Women: Relationship to Metabolic Syndrome and Atherogenic Risk
}

\author{
Muthuvel Jayachandran • Robert D. Litwiller • Brian D. Lahr • Kent R. Bailey • \\ Whyte G. Owen • Sharon L. Mulvagh • John A. Heit • Howard N. Hodis • \\ S. Mitchell Harman • Virginia M. Miller
}

Received: 17 March 2011 / Accepted: 13 June 2011 /Published online: 24 July 2011

(C) The Author(s) 2011. This article is published with open access at Springerlink.com

\begin{abstract}
A woman's risk for metabolic syndrome (MS) increases at menopause, with an associated increase in risk for cardiovascular disease. We hypothesized that early menopause-related changes in platelet activity and concentrations of microvesicles derived from activated blood and vascular cells provide a mechanistic link to the early atherothrombotic process. Thus, platelet functions and cellular origin of blood-borne microvesicles in recently menopausal women $(n=118)$ enrolled in the Kronos Early Estrogen Prevention Study were correlated with components of MS and noninvasive measures of cardiovascular disease [carotid artery intima medial thickness (CIMT), coronary artery calcium (CAC) score, and endothelial reactive hyperemic index (RHI)]. Specific to individual components of the MS pentad, platelet number increased with increasing waist
\end{abstract}

M. Jayachandran • V. M. Miller $(\bowtie)$

Department of Physiology \& Biomedical Engineering,

Mayo Clinic,

200 First St. SW,

Rochester, MN 55905, USA

e-mail: miller.virginia@mayo.edu

R. D. Litwiller · W. G. Owen · J. A. Heit

Department of Internal Medicine Division of Hematology,

Mayo Clinic,

Rochester, MN 55905, USA

B. D. Lahr $\cdot$ K. R. Bailey

Department of Health Sciences Research Division

of Biomedical Statistics and Informatics,

Mayo Clinic,

Rochester, MN 55905, USA

W. G. Owen

Department of Biochemistry \& Molecular Biology, Mayo Clinic,

Rochester, MN 55905, USA circumference, and platelet secretion of ATP and expression of P-selectin decreased with increasing blood glucose $(p=$ $0.005)$ and blood pressure $(p<0.05)$, respectively. Waist circumference and systolic blood pressure were independently associated with monocyte- and endothelium-derived microvesicles $(p<0.05)$. Platelet-derived and total procoagulant phosphatidylserine-positive microvesicles, and systolic blood pressure correlated with CIMT $(p<0.05)$, but not with CAC or RHI. In summary, among recently menopausal women, specific platelet functions and concentrations of circulating activated cell membrane-derived procoagulant microvesicles change with individual components of MS. These cellular changes may explain in part how menopause contributes to MS and, eventually, to cardiovascular disease.

S. L. Mulvagh · J. A. Heit

Division of Cardiovascular Diseases,

Mayo Clinic,

Rochester, MN 55905, USA

V. M. Miller

Department of Surgery, Mayo Clinic,

Rochester, MN 55905, USA

H. N. Hodis

Atherosclerosis Research Unit, University of Southern California,

Los Angeles, CA 90033, USA

S. M. Harman

Kronos Longevity Research Institute,

Phoenix, AZ 85016, USA 
Keywords Atherosclerosis · Carotid intima medial thickening · Coronary calcification · Endothelial function . Monocytes $\cdot$ Platelet secretion

\section{Introduction}

The risk for developing cardiovascular disease in women increases after menopause, in part because of susceptibility to developing metabolic syndrome [1-3]. Metabolic syndrome is characterized by the presence of three of five clinical parameters including: waist circumference $>35$ in. $(>88 \mathrm{~cm})$, high-density lipoprotein cholesterol (HDL-C) $<50 \mathrm{mg} / \mathrm{dL}$, triglyceride level $>150 \mathrm{mg} / \mathrm{dL}$, fasting blood glucose $>100 \mathrm{mg} / \mathrm{dL}$, and systemic blood pressure (systolic blood pressure $\geq 130$ or diastolic blood pressure $\geq 85 \mathrm{mmHg}$ ) $[4,5]$. Using that characterization, two individuals may be described with metabolic syndrome, but the underlying pathways affecting specific vascular or metabolic functions may differ. A components model of metabolic syndrome identified an association of high triglycerides and hypertension with myocardial infarction and stroke in a subset of women (20-89 years of age) sampled in the Third National Health and Nutrition Examination Study (NHANES III) [6]. However, precise mechanisms by which components of the metabolic syndrome may contribute, equally or synergistically, to early processes of cardiovascular disease are unknown.

Platelets, derived from megakaryocytes in the bone marrow, are blood-borne elements implicated in the progression of cardiovascular disease [7-10]. Platelets turnover within about a 10-day period, during which time changes in the reactivity of individual platelets may progress through stages of aggregation, secretion, adhesion, expression of procoagulant surface (phosphatidylserine, P-selectin, and fibrinogen receptors), and shedding of thrombogenic membrane vesicles. This turnover is influenced by hormonal and metabolic influences on the megakaryocytes $[11,12]$. No studies have evaluated the relationships of platelet functions and metabolic syndrome with subclinical measures of atherosclerosis in asymptomatic but at-risk population.

Activated platelets, as well as other vascular cells, release membrane-derived microvesicles [13, 14]. Populations of prothrombotic cell membrane-derived microvesicles increased with the presence of arterial calcification in otherwise healthy menopausal women [15] and with metabolic syndrome [16, 17]. Therefore, further analysis of the cellular origin of circulating microvesicles may provide insight into the activation of the vasculature with metabolic syndrome in the earliest stages of cardiovascular disease. This study was designed to evaluate platelet characteristics and activated vascular and blood cell-derived microvesicles with components of metabolic syndrome in recently menopausal women in whom the overall immediate cardiovascular disease risk is low but longitudinal risk will increase due to their menopausal status [18-20]. It was hypothesized that platelet reactivity and platelet-derived microvesicles would correlate positively with components of metabolic syndrome, carotid artery intima medial thickness (CIMT), and coronary arterial calcification (CAC) but negatively correlate with peripheral forearm reactive hyperemia.

\section{Methods}

Subjects

Study subjects were recently menopausal women (42-59 years old, within 6 months to 3 years of their last menses) without known or suspected cardiovascular disease and meeting the inclusion criteria for the Kronos Early Estrogen Prevention Study (KEEPS; NCT000154180) enrolled at the Mayo Clinic, Rochester, MN [21]. KEEPS is a multicenter, randomized, double-blinded, placebo-controlled trial designed to test the hypothesis that hormone therapy started early in menopause will reduce the onset, incidence, and progression of subclinical atherosclerosis as defined by measurable changes in CIMT and CAC. Each potential subject underwent a medical examination, including body morphometrics (body mass index, waist/hip ratio measurements), standard blood chemistries, and an electrocardiogram. All women $(n=118)$ underwent high-resolution B-mode ultrasound for the assessment of CIMT [22] and computed tomography for the assessment of CAC (Siemens Sensation 64, Siemens Medical Solutions, Forcheim, Germany) [15, 18]. A subset of women $(n=95)$ had assessment of forearm reactive hyperemia by digital tonometry (reactive hyperemic index or RHI) [23]. Women were excluded from KEEPS if they had a history of clinically defined cardiovascular disease; were current heavy smokers (more than ten cigarettes/day by self-report); their CAC score was $\geq 50$ Agatston units (AU); body mass index was $>35 \mathrm{~kg} / \mathrm{m}^{2}$; or if they had dyslipidemia (low-density lipoprotein cholesterol $>190 \mathrm{mg} / \mathrm{dL}$ ), hypertriglyceridemia (triglycerides, $>400 \mathrm{mg} / \mathrm{dL}$ ), $17 \beta$-estradiol $>40 \mathrm{mg} / \mathrm{dL}$, uncontrolled hypertension (systolic blood pressure $>150 \mathrm{mmHg}$ and/or diastolic blood pressure $>95 \mathrm{mmHg}$ ), or fasting blood glucose $>126 \mathrm{mg} / \mathrm{dL}[18$, 21]. This study was approved by the Mayo Clinic Institutional Review Board (IRB no. 2241-04 and no. 09-003464). All participants gave written informed consent. For the present study, we used blood samples from women $(n=118)$ meeting the KEEPS inclusion criteria at Mayo Clinic Rochester; all samples were collected at baseline and prior to randomization to study treatments. 


\section{Blood Chemistries}

Total cholesterol, low-density lipoprotein cholesterol (LDLC) and HDL-C, triglycerides, blood glucose, folliclestimulating hormone, $17 \beta$ estradiol, thyroid-stimulating hormone, high-sensitivity C-reactive protein (hs-CRP) and total protein, albumin, bilirubin, alkaline phosphatase, aspartate, and alanine transaminases were measured by Kronos Science Laboratories (Phoenix, AZ) and the Mayo Clinic Department of Laboratory Medicine and Pathology (Rochester, MN). Total white blood cells, differential leukocytes, hemoglobin, and hematocrit were determined by Mayo Clinic Hematopathology Laboratories. Platelet count was determined by Coulter counter.

\section{Blood Collection and Platelet Reactivity Assays}

No participant was diabetic or taking lipid-lowering drugs (inclusion criteria). Women were asked to refrain from using aspirin for 10 days prior to the blood collection. Fasting venous blood was collected into a syringe from an antecubital venipuncture with a 19-gauge butterfly needle. Blood was dispensed into plastic tubes containing anticoagulants needed for each assay as indicated below and maintained at $33^{\circ} \mathrm{C}$ until the test was performed. To provide consistency for platelet collection and handling, all samples were processed within $30 \mathrm{~min}$ of collection by the same individuals. With these collection techniques, platelet activation as determined by basal expression of P-selectin and fibrinogen receptors is $<5 \%$ [15].

Platelet microaggregation was measured as the quotient of platelet counts in blood samples collected in citrate and EDTA anticoagulants [24, 25] and is reported as the percentage of the difference. Platelet counts were corrected for dilution by citrate anticoagulant; there was no significant dilution in EDTA.

Platelet dense body ATP secretion from diluted plateletrich plasma was measured in real time by bioluminescence using premixed firefly luciferase $(0.5 \mathrm{mg} / \mathrm{mL}$ Hanks' medium) and luciferin ( $5 \mathrm{mM}$ in Hanks' medium) at $32^{\circ} \mathrm{C}$ and a final platelet concentration of approx. 250-500 platelets/ $\mu \mathrm{L}$ [26]. In brief, platelet-rich plasma prepared from citrate whole blood and from blood anticoagulated with thrombin inhibitor (hirudin, micromolar final) and a Factor $\mathrm{Xa}$ inhibitor [10 $\mu \mathrm{M}$, tick anticoagulant peptide (TAP) or soy bean trypsin inhibitor (SBTI)] centrifugation at $200 \times \mathrm{g}$ for $15 \mathrm{~min}$ was diluted into 500-1000 volumes of Hanks' medium (Hanks' balanced salt solution buffered to $\mathrm{pH} 7.4$ with $20 \mathrm{mM}$ HEPES and containing $3 \mathrm{mg} / \mathrm{mL}$ bovine albumin, $0.4 \mathrm{~g} / \mathrm{L}$ glucose, and $1 \mu \mathrm{M}$ TAP or SBTI). Thrombin receptor agonist peptide (TRAP, $10 \mu \mathrm{M}$ ) was used as agonist for ATP secretion assay. Dense body ATP secretion is expressed as attomoles (amol)/platelet.
Platelet $P G E_{1}$ sensitivity is a surrogate measure for prostacyclin, which raises cAMP and thereby inhibits platelet responses to agonists, including TRAP. This assay is carried out in tandem with the ATP secretion assay. Prior to assay, diluted platelets $(250-500 / \mu \mathrm{L})$ in Hanks' medium were incubated with $\mathrm{PGE}_{1}(\sim 500 \mathrm{nM})$ for $10 \mathrm{~min}$ at $32^{\circ} \mathrm{C}$. $\mathrm{PGE}_{1}$ sensitivity is expressed as percent suppression of dense body ATP secretion.

Platelet membrane expression of P-selectin and the fibrinogen-binding conformation of receptor integrin $\alpha_{I I b} \beta_{3}$ were measured by flow cytometry [24] with the following modifications [15]. Platelets in whole blood (anticoagulated with hirudin and Factor Xa inhibitor) were diluted 1:100 in Hanks' medium and then stimulated with agonist, ADP $(100 \mu \mathrm{M})$ or STRAP $(10 \mu \mathrm{M})$, for $10 \mathrm{~min}$. Platelets were then stained with anti-GPIIIa (CD61) plus anti-P-selectin and CD61 plus anti- $\alpha_{\text {IIB }} \beta_{3}$ (PAC1) antibodies for $30 \mathrm{~min}$ at room temperature. Platelets were fixed with $1 \%$ paraformaldehyde in HEPES-buffered saline (HBS) prior to analysis by flow cytometry (FACScalibur ${ }^{\mathrm{TM}}$, Becton Dickinson). Forward scatter (for size characteristic) and log side scatter (for refractive index) with CD61 antibody were used to identify platelets. The platelet cloud was gated to exclude red and white blood cells. Surface expressions of P-selectin and fibrinogen receptors are expressed as percent positive.

\section{Plasma-Activated Protein C}

Mouse anti-human APC (HAPC 1555) was bound to magnetic beads coated with goat anti-mouse IgG. Beads were separated from liquid by use of an EasySep ${ }^{\mathrm{TM}}$ magnet (StemCell Technologies Seattle, WA). Beads from $2.5 \mathrm{~mL}$ of the suspension provided by the manufacturer were washed with $3 \times 1 \mathrm{~mL}$ of $0.15 \mathrm{M} \mathrm{NaCl}, 5 \mathrm{mM} \mathrm{CaCl}_{2}$, $0.02 \mathrm{M} \mathrm{Na}-\mathrm{HEPES}, \mathrm{pH} 7.5$ (HBS+Ca(II)). Beads were then mixed with $0.5 \mathrm{~mL}$ of the anti-aPC $(350 \mu \mathrm{g} / \mathrm{mL}$ in the same buffer) for $5 \mathrm{~h}$ on a rotary mixer. Beads bound one half of the protein as determined by the BCA protein assay. Beads were suspended in $1.5 \mathrm{~mL}$ of $0.1 \mathrm{M} \mathrm{NaCl}, 0.02 \%$ $\mathrm{NaN}_{3}$, and $0.05 \mathrm{M}$ Tris- $\mathrm{Cl}, \mathrm{pH} 7.4$, and stored at $4^{\circ} \mathrm{C}$ until used. On the week of planned use, the anti-aPC beads were blocked with bovine serum albumin (BSA). In a $1.5-\mathrm{mL}$ polypropylene tube, $30 \mu \mathrm{L}$ of beads, $1 \mathrm{~mL} 1 \%$ BSA in $\mathrm{HBS}+\mathrm{Ca}(\mathrm{II}), 10 \mu \mathrm{L}$ of $10 \% \mathrm{NP} 40$, and $10 \mu \mathrm{L}$ of $10 \% \mathrm{PEG}$ 8000 were mixed on a rotary mixer for $1 \mathrm{~h}$. The blocked beads were then stored in the blocking solution at $4^{\circ} \mathrm{C}$ until used. Venous blood ( $4 \mathrm{~mL})$ was added to a tube containing $0.5 \mathrm{~mL}$ of $0.11 \mathrm{M}$ sodium citrate and $0.1 \mathrm{~mL}$ of $1 \mathrm{M}$ benzamidinium $\mathrm{Cl}$. Plasma was prepared within $30 \mathrm{~min}$ of phlebotomy, and $1 \mathrm{~mL}$ of the plasma was added to the blocked anti-aPC beads from which the blocking solution had been removed and to which $15 \mu \mathrm{L}$ of $100 \mu \mathrm{M}$ hirudin in HBS and $50 \mu \mathrm{L}$ of a mixture of $1 \mathrm{M} \mathrm{CaCl}_{2}$ in HBS, $1 \mathrm{M}$ 
Na-HEPES ( $\mathrm{pH} 7.5$ ), 10\% NP40, and 10\% PEG 8000 $(1: 2: 1: 1)$ had been added. Plasma was mixed with the beads on a rotary mixer for $90-180 \mathrm{~min}$. Beads were washed and assayed for bound plasma-activated protein $\mathrm{C}(\mathrm{aPC})$ with fluorescent substrate SN-59 (D-Val-Pro-Arg-6-amino-1naphthalene sulfonamide). Assays were carried out in duplicate. For a standard curve, authentic human aPC was added to $1 \mathrm{~mL}$ of $1 \%$ BSA in $\mathrm{HBS}+\mathrm{Ca}$ (II) plus $15 \mu \mathrm{L}$ of $100 \mu \mathrm{M}$ hirudin and $50 \mu \mathrm{L}$ of a mixture $(1: 2: 1: 1)$ of $1 \mathrm{M}$ $\mathrm{CaCl}_{2}, 1 \mathrm{M}$ Na-HEPES (pH 7.5), 10\% NP40, and $10 \%$ PEG 8000 . The standard solutions were added to blocked aPC beads, mixed, and assayed with the plasma samples. Standards prepared by adding aPC to pooled normal human citrated plasma from $\mathrm{CRYOcheck}^{\mathrm{TM}}$ gave equivalent results.

\section{Microvesicles}

The cellular origin and expression of the procoagulant (phosphatidylserine) surface of the circulating population of microvesicles (MV) were determined in platelet-free plasma from hirudin and SBTI anticoagulated blood as described previously [15]. Platelet-free plasma was prepared within $30 \mathrm{~min}$ of blood collection and stored at $-70^{\circ} \mathrm{C}$ until analysis.

\section{Materials}

The TRAP $\left(\mathrm{H}_{2} \mathrm{~N}\right.$-Ser-4-fluoro-Phe-2-naphthyl-Ala-LeuArg- $\mathrm{CONH}_{2}$ ) was synthesized by our laboratory. TAP, hirudin, and mouse anti-human aPC were gifts from Dr. H. Grossenbacher, CIBA-GEIGY, and Dr. Charles Esmon, University of Oklahoma, respectively. All conjugated/ fluorescent antibodies (fluorescein and phycoerythrin) and recombinant annexin $\mathrm{V}$ were purchased from BD Biosciences, San Jose, CA; goat anti-mouse IgG magnetic beads (MagnaBind ${ }^{\mathrm{TM}}$ ) were purchased from Pierce, Rockford, IL; luciferase and luciferin from Roche Applied Science, Indianapolis, IN; and aPC and SN-59 from HaemTech, Essex Junction, VT. The other chemicals were purchased from either Sigma Chemical Co, St. Louis, MO, Electron Microscopy Science, Hatfield, PA, or EMD Chemicals, Gibbstown, NJ.

\section{Statistical Analyses}

Descriptive statistics were used to summarize the cohort including means with standard deviations (SD) and medians with interquartile ranges $(\mathrm{Q} 1, \mathrm{Q} 3)$ for all continuous parameters. To explore the relationship with waist circumference, descriptive statistics of participant characteristics and makers of platelet function were also reported for each of three strata defined by waist circumference $<30,30 \leq 35$, and $>35$ in. The linear relationship between waist circumference and each clinical parameter was assessed using Spearman correlation $(\rho)$. Similar correlation analyses were performed for each component of metabolic syndrome with markers of platelet function. For testing independent associations, multivariable linear regression was performed with each platelet parameter modeled using the primary components of metabolic syndrome as the explanatory variables. Due to skewed distributions for most of the platelet and microvesicle parameters as well as for triglycerides and fasting blood glucose, a probit transformation was applied to the ranked values of each, thus producing normal distributional properties. To avoid the issue of co-linearity between the two blood pressure parameters, only systolic blood pressure was included as a covariate in multivariable regression models.

All analyses were performed using the SAS statistical software package (version 9.1, SAS Institute Inc., Cary, NC). With a sample size of 100 subjects, a correlation coefficient of 0.28 would have been detectable with $80 \%$ power at a significance level of 0.05 . Although multiple hypothesis tests were carried out, a nominal two-sided significance level of 0.05 was used with no formal adjustment for multiple testing. Given that about 120 pairwise correlations were tested, the expected number of about four to six nominally significant results by chance alone should be considered in the interpretation of these findings.

\section{Results}

\section{General Characteristics of Participants}

The median (range) participant age and months past menopause were 52 (range, 45-58)years and 19 (3.635.8) months, respectively. Based on the inclusion criteria for KEEPS participants, traditional cardiovascular risk factors (Table 1) defining the 10-year cardiovascular risk (Framingham score $\leq 1$ ) were low in these women. All parameters in the complete blood count were within normal ranges for all subjects (Table 2). As per the study entry criteria, the CAC score for all women was $<50 \mathrm{AU}$, with the majority $(n=102,86.4 \%)$ having a score of zero. Median (IQR) values for CIMT and RHI were 0.7 (0.6, $0.8) \mathrm{mm}$ and $2.4(1.9,2.5)$, respectively.

\section{General Platelet Functions}

Spontaneous platelet microaggregation ranged from $0 \%$ to $4.5 \%$. ATP secretion from dense granules of platelets and its inhibition by $\mathrm{PGE}_{1}$ were similar in platelets isolated from blood collected in citrate and hirudin plus TAP or SBTI anticoagulant (Table 3). Basal expression of P-selectin and 
Table 1 General characteristics of women in whom platelet functions were determined

$n=118$

$H D L-C$ high-density lipoprotein cholesterol, $L D L-C$ low-density lipoprotein cholesterol, $h s-C R P$ high-sensitivity $\mathrm{C}$-reactive protein

\begin{tabular}{lccc}
\hline Characteristic & Mean \pm SD & Median & IQR: Q1, Q3 \\
\hline Age (years) & $52.4 \pm 2.4$ & 52.0 & $51.0,58.0$ \\
Menopausal age (months) & $19.3 \pm 9.1$ & 19.0 & $11.7,25.8$ \\
Follicle stimulating hormone (mIU/L) & $86.2 \pm 33.7$ & 79.0 & $62.6,107.0$ \\
$17 \beta$-estradiol (pg/mL) & $22.0 \pm 9.1$ & 20.0 & $20.0,21.0$ \\
Thyroid stimulating hormone (mIU/mL) & $2.2 \pm 1.2$ & 2.1 & $10.3,3.0$ \\
Body mass index (kg/m $\left.{ }^{2}\right)$ & $27.1 \pm 4.2$ & 26.7 & $24.1,30.7$ \\
Waist circumference $(\mathrm{cm}), n=114$ & $84.4 \pm 11.9$ & 83.3 & $76.0,91.0$ \\
Fasting glucose $(\mathrm{mg} / \mathrm{dL}), n=115$ & $92.5 \pm 8.3$ & 92.0 & $87.0,98.0$ \\
Total cholesterol (mg/dL), $n=115$ & $217.6 \pm 30.7$ & 218.0 & $200.0,238.0$ \\
HDL-C (mg/dL), $n=115$ & $61.1 \pm 15.3$ & 61.0 & $50.0,70.0$ \\
LDL-C (mg/dL), $n=115$ & $133.1 \pm 29.6$ & 136.0 & $114.0,150.0$ \\
Triglycerides $(\mathrm{mg} / \mathrm{dL}), n=115$ & $95.8 \pm 46.7$ & 85.0 & $66.0,117.0$ \\
Systolic blood pressure $(\mathrm{mmHg})$ & $122.2 \pm 14.0$ & 121.0 & $112.5,130.0$ \\
Diastolic blood pressure $(\mathrm{mmHg})$ & $75.4 \pm 8.0$ & 76.0 & $70.0,82.0$ \\
hs-CRP (pg/mL), $n=112$ & $2.0 \pm 2.2$ & 1.3 & $0.6,2.4$ \\
\hline
\end{tabular}

PAC-1 binding was $<5 \%$. Nearly all platelets secreted $\alpha$ granules in response to TRAP as determined by the expression of surface P-selectin, in contrast to the response to ADP which showed a substantial distribution of values (Table 3). In contrast, the percentage of platelets expressing the fibrinogen-binding conformation of integrin $\alpha_{\mathrm{IIb}} \beta_{3}$ as reflected by PAC-1 binding was greater in response to ADP than to TRAP, which activated PAC1 binding in fewer than $20 \%$ of platelets in most samples (Table 3). Plasma concentration of aPC, a reflection of endogenous thrombin generation or endothelial protein $\mathrm{C}$ receptor (EPCR) expression, ranged from 0 to $10.6 \mathrm{ng} / \mathrm{mL}(n=116)$.

Correlation of Platelet Functions with Criteria for Metabolic Syndrome

Sixty-three of 118 women had at least one of the pentad characterizing metabolic syndrome. Twenty of 118 women (14\%) met the criteria for metabolic syndrome. Only ATP secretion from platelets was significantly different between women, defined as having metabolic syndrome compared with those without (Table 4). Combinations of criterion by which women met the definition for metabolic syndrome were heterogeneous (Table 5). Since waist circumference was the only consistent parameter identifying women with metabolic syndrome, other cardiovascular risk factors were summarized by waist circumference groupings and tested for a correlation with continuous values for waist circumference (Table 6). With the exception of age and $\mathrm{aPC}$, the other clinical cardiovascular risk factors evaluated in this study demonstrated a significant correlation with waist circumference (Table 6).

Platelet characteristics and functions that correlated with components of metabolic syndrome included total number of platelets which correlated positively with waist circumference. Inhibition of ATP secretion by $\mathrm{PGE}_{1}$ correlated positively with waist circumference in platelets collected in hirudin and negatively with HDL-C regardless of the anticoagulant (Table 7). ATP secretion correlated negatively with fasting blood glucose. Basal expression of P-selectin
Table 2 Blood cell counts in women in whom platelets were studied
${ }^{\mathrm{a}} n=114$

${ }^{\mathrm{b}} n=116$

\begin{tabular}{lccc}
\hline Variable $(n=118)$ & Mean $\pm \mathrm{SD}$ & Median & IQR: Q1, Q3 \\
\hline Hemoglobin (g/dL) & $13.7 \pm 0.8$ & 13.8 & $13.2,14.2$ \\
Hematocrit (\%) & $39.8 \pm 2.2$ & 39.7 & $38.4,41.1$ \\
Platelets (in citrate, $\left.10^{3} / \mu \mathrm{L}\right)^{\mathrm{a}}$ & $235.3 \pm 49.1$ & 232.0 & $201.0,267.0$ \\
Platelets (in EDTA, $\left.10^{3} / \mu \mathrm{L}\right)^{\mathrm{b}}$ & $240.6 \pm 49.1$ & 234.5 & $209.0,269.5$ \\
WBC $\left(10^{9} / \mathrm{L}\right)$ & $5.3 \pm 1.4$ & 5.0 & $4.2,6.3$ \\
Neutrophils (\%) & $57.9 \pm 6.9$ & 58.0 & $53.0,62.0$ \\
Lymphocytes (\%) & $31.8 \pm 6.5$ & 31.0 & $27.0,36.0$ \\
Monocytes (\%) & $7.1 \pm 1.7$ & 7.0 & $6.0,8.0$ \\
Eosinophils (\%) & $2.4 \pm 1.6$ & 2.0 & $1.0,3.0$ \\
Basophils (\%) & $0.5 \pm 0.5$ & 0.0 & $0.00,1.00$ \\
\hline
\end{tabular}


Table 3 Summary of platelet functions in recently menopausal women
$A D P$ adenosine diphosphate, ATP adenosine triphosphate, $P A C 1$ integrin $\alpha_{\text {IIB }} \beta_{3}$ fibrinogen binding, $P G E_{1}$ prostaglandin $\mathrm{E}_{1}$, plt platelet, TAP tick anticoagulant peptide, TRAP thrombin receptor agonist peptide

\begin{tabular}{llcc}
\hline Platelet function & Mean \pm SD & Median & IQR: Q1, Q3 \\
\hline ATP secretion (amol/plt) & & & \\
$\quad$ Citrate, $n=110$ & $25.0 \pm 7.8$ & 24.3 & $20.1,28.9$ \\
$\quad$ Hirudin plus TAP or soybean trypsin inhibitor, $n=99$ & $27.1 \pm 9.3$ & 26.4 & $21.0,32.8$ \\
PGE 1 sensitivity (\% inhibition ATP secretion) & & & \\
$\quad$ Citrate, $n=108$ & $22.3 \pm 14.9$ & 21.3 & $10.7,32.8$ \\
Hirudin plus TAP or soybean trypsin inhibitor, $n=99$ & $22.2 \pm 15.3$ & 20.7 & $10.8,31.3$ \\
Basal $\%$ expression & & & \\
P-Selectin, $n=112$ & $2.1 \pm 1.1$ & 1.9 & $1.4,2.6$ \\
PAC-1 binding, $n=114$ & $1.0 \pm 0.6$ & 0.9 & $0.6,1.2$ \\
P-Selectin (\% positive) & & & \\
ADP, $n=112$ & $65.1 \pm 11.9$ & 67.3 & $55.9,75.2$ \\
TRAP, $n=114$ & $91.8 \pm 3.2$ & 92.2 & $90.3,94.1$ \\
PAC-1 $(\%$ positive) & & & \\
ADP, $n=114$ & $75.3 \pm 15.5$ & 78.6 & $67.4,88.4$ \\
TRAP, $n=115$ & $15.4 \pm 10.0$ & 14.1 & $8.1,20.5$ \\
\hline
\end{tabular}

and activated expression of P-selectin in response to ADP stimulation correlated negatively with both systolic and diastolic blood pressures. None of the studied platelet functions were significantly correlated with triglycerides by univariate assessment.

Among the subset of subjects in whom plasma microvesicles were measured $(n=58)$, neither total number of procoagulant (phosphatidylserine-positive by annexin $\mathrm{V}$ binding) microvesicles or those expressing vascular cell adhesion molecule-1 or tissue factor correlated with any of the components of metabolic syndrome (data not shown).
Microvesicles expressing intercellular adhesion molecule-1 (ICAM-1) correlated with triglycerides $(\rho=0.32, p=0.017)$. Microvesicles derived from monocytes (CD14) correlated positively with systolic blood pressure $(\rho=0.31, p=0.016)$; other microvesicles [platelets (CD42a), leukocytes (CD45), or endothelium-(CD62) derived] did not correlate significantly with any component of metabolic syndrome from the univariate analysis (Table 7).

Multivariable regression revealed a few strong independent associations between components of metabolic syndrome and different platelet functions (Table 7). Among
Table 4 Platelet functions in recently menopausal women with and without metabolic syndrome
$A D P$ adenosine diphosphate, $A T P$ adenosine triphosphate, $P A C 1$ integrin $\alpha_{\text {IIB }} \beta_{3}$ fibrinogen binding, $P G E_{I}$ prostaglandin $\mathrm{E}_{1}$, plt platelet, TAP tick anticoagulant peptide, TRAP thrombin receptor agonist peptide

\begin{tabular}{|c|c|c|c|c|c|}
\hline \multirow[t]{2}{*}{ Variable } & \multicolumn{2}{|c|}{ No metabolic syndrome } & \multicolumn{2}{|c|}{ Metabolic syndrome } & \multirow[t]{2}{*}{$p$ value } \\
\hline & $n$ & & $n$ & & \\
\hline \multicolumn{6}{|l|}{ ATP Secretion (amol/plt) } \\
\hline Citrate & 86 & $25.1(20.5,31.7)$ & 20 & $22.2(19.2,24.1)$ & 0.01 \\
\hline $\begin{array}{l}\text { Hirudin plus TAP or soybean } \\
\text { trypsin inhibitor }\end{array}$ & 78 & $27.9(21.0,33.8)$ & 17 & $23.8(21.7,26.4)$ & 0.05 \\
\hline \multicolumn{6}{|c|}{$\mathrm{PGE}_{1}$ sensitivity (\% inhibition ATP secretion) } \\
\hline Citrate & 85 & $18.8(9.7,28.6)$ & 19 & $23.8(20.3,36.7)$ & 0.09 \\
\hline $\begin{array}{l}\text { Hirudin plus TAP or soybean } \\
\text { trypsin inhibitor }\end{array}$ & 78 & $19.5(10.6,28.1)$ & 17 & $24.6(13.0,37.0)$ & 0.23 \\
\hline \multicolumn{6}{|l|}{ Basal $\%$ expression } \\
\hline P-Selectin & 90 & $2.0(1.4,2.6)$ & 18 & $1.6(1.3,2.8)$ & 0.78 \\
\hline PAC-1 binding & 91 & $0.9(0.6,1.2)$ & 19 & $1.0(0.7,1.3)$ & 0.35 \\
\hline \multicolumn{6}{|l|}{ P-Selectin (\% positive) } \\
\hline ADP & 89 & $68.6(58.7,75.5)$ & 19 & $57.7(52.3,75.1)$ & 0.09 \\
\hline TRAP & 90 & $92.4(90.3,94.4)$ & 20 & $91.4(89.9,92.9)$ & 0.13 \\
\hline \multicolumn{6}{|l|}{ PAC-1 (\% positive) } \\
\hline ADP & 91 & $77.6(67.4,87.9)$ & 19 & $(55.4,88.4)$ & 0.73 \\
\hline TRAP & 92 & $14.2(8.4,20.8)$ & 19 & $(5.3,19.1)$ & 0.67 \\
\hline
\end{tabular}


Table 5 Components of metabolic syndrome in women within 3 years of menopause

\begin{tabular}{|c|c|c|c|c|c|c|}
\hline Participant & WC & HDL-C & FBG & Trig & SBP & DBP \\
\hline A & $\mathrm{Y}$ & & & Y & Y & Y \\
\hline B & $\mathrm{Y}$ & & Y & & $\mathrm{Y}$ & \\
\hline $\mathrm{C}$ & $\mathrm{Y}$ & $\mathrm{Y}$ & $\mathrm{Y}$ & & & \\
\hline D & Y & $\mathrm{Y}$ & Y & $\mathrm{Y}$ & & \\
\hline E & $\mathrm{Y}$ & $\mathrm{Y}$ & & & $\mathrm{Y}$ & Y \\
\hline F & $\mathrm{Y}$ & $\mathrm{Y}$ & Y & Y & Y & \\
\hline G & $\mathrm{Y}$ & $\mathrm{Y}$ & & Y & & \\
\hline $\mathrm{H}$ & $\mathrm{Y}$ & & Y & & Y & \\
\hline I & $\mathrm{Y}$ & $\mathrm{Y}$ & Y & Y & & \\
\hline $\mathrm{J}$ & $\mathrm{Y}$ & $\mathrm{Y}$ & Y & Y & & \\
\hline K & $\mathrm{Y}$ & $\mathrm{Y}$ & & $\mathrm{Y}$ & Y & \\
\hline $\mathrm{L}$ & $\mathrm{Y}$ & Y & Y & $\mathrm{Y}$ & $\mathrm{Y}$ & $\mathrm{Y}$ \\
\hline M & $\mathrm{Y}$ & & $\mathrm{Y}$ & & $\mathrm{Y}$ & \\
\hline $\mathrm{N}$ & $\mathrm{Y}$ & Y & Y & & & \\
\hline $\mathrm{O}$ & $\mathrm{Y}$ & & & $\mathrm{Y}$ & & $\mathrm{Y}$ \\
\hline $\mathrm{P}$ & $\mathrm{Y}$ & Y & Y & & & \\
\hline Q & Y & $\mathrm{Y}$ & & $\mathrm{Y}$ & Y & \\
\hline $\mathrm{R}$ & $\mathrm{Y}$ & $\mathrm{Y}$ & Y & & Y & Y \\
\hline $\mathrm{S}$ & Y & $\mathrm{Y}$ & & Y & & \\
\hline $\mathrm{T}$ & $\mathrm{Y}$ & Y & Y & & & \\
\hline Total & 20 & 15 & 13 & 11 & 10 & 5 \\
\hline
\end{tabular}

$D B P$ diabolic blood pressure, $F B G$ fasting blood glucose, $H D L-C$ high-density lipoprotein cholesterol, $S B P$ systolic blood pressure, Trig triglycerides, $W C$ waist circumference, $Y$ yes these, platelet number retained its association with waist circumference independent of the other components of metabolic syndrome, as did fasting blood glucose with ATP secretion. Also detected were independent associations for monocyte-derived microvesicles (CD14) with waist circumference as well as with systolic blood pressure (Table 8).

Relationship of Platelet Functions to Measures of Vascular Anatomy and Endothelial Function

CAC scores showed a positive correlation with triglycerides ( $\rho=0.19, p=0.048)$. Age, systolic blood pressure, and total cholesterol correlated with CIMT $(\rho=0.20, p=0.031 ; \rho=$ $0.22, p=0.015$; and $\rho=0.19, p=0.046$, respectively). None of the measured platelet functions correlated with RHI or CAC. However, both platelet-derived microvesicles (CD42a) and annexin V-positive microvesicles correlated with CIMT ( $\rho=$ $0.29, p=0.028$ and $\rho=0.33, p=0.010$, respectively; $n=58$ ).

\section{Discussion}

This study provides the first comprehensive analysis of platelet functions and cell-derived microvesicles in a group of women in whom overall immediate cardiovascular disease risk is low but longitudinal risk will increase due to their menopausal status [18-20]. The present study identifies unique platelet characteristics and their relationship to modifiable cardiovascular risk factors contributing

Table 6 Cardiovascular risk factors and waist circumference (WC) in newly menopausal women

\begin{tabular}{|c|c|c|c|c|c|c|c|c|c|}
\hline \multirow[t]{2}{*}{ Risk factor } & \multicolumn{2}{|c|}{$\mathrm{WC}<30$ in. $(n=27)$} & \multicolumn{2}{|c|}{ WC $30-35$ in. $(n=45)$} & \multicolumn{2}{|c|}{$\mathrm{WC}>35$ in. $(n=42)$} & \multicolumn{2}{|c|}{$\begin{array}{l}\text { Spearman correlation }{ }^{\mathrm{a}} \\
\left(n=114^{\mathrm{b}}\right)\end{array}$} & \multirow[t]{2}{*}{$p$ value } \\
\hline & Median & IQR & Median & IQR & Median & IQR & $\rho$ & $95 \% \mathrm{CI}$ & \\
\hline Age & 52.0 & $(51.0,53.0)$ & 52.0 & $(51.0,54.0)$ & 53.0 & $(51.0,54.0)$ & 0.08 & $(-0.10-0.26)$ & 0.379 \\
\hline Menopausal Mo & 16.7 & $(12.5,21.1)$ & 19.2 & $(9.6,25.4)$ & 21.1 & $(13.3,29.9)$ & 0.22 & $(0.04-0.39)$ & 0.016 \\
\hline SBP & 119.0 & $(106.5,126.0)$ & 119.0 & $(110.0,129.5)$ & 128.0 & $(121.0,135.5)$ & 0.39 & $(0.22-0.54)$ & 0.001 \\
\hline DBP & 71.0 & $(65.5,80.0)$ & 74.0 & $(70.0,80.0)$ & 79.0 & $(73.5,84.0)$ & 0.33 & $(-0.16-0.48)$ & 0.001 \\
\hline Fasting glucose & 88.0 & $(86.0,96.0)$ & 93.0 & $(88.0,96.0)$ & 93.0 & $(87.0,102.0)$ & 0.26 & $(0.08-0.43)$ & 0.005 \\
\hline TC & 209.0 & $(183.0,219.0)$ & 218.0 & $(203.0,241.0)$ & 227.0 & $(210.0,240.0)$ & 0.18 & $(0.00-0.35)$ & 0.053 \\
\hline LDL-C & 122.0 & $(96.0,143.0)$ & 136.0 & $(117.0,152.0)$ & 144.0 & $(120.0,163.0)$ & 0.29 & $(0.11-0.45)$ & 0.002 \\
\hline HDL-C & 68.0 & $(62.0,77.0)$ & 61.0 & $(51.0,70.0)$ & 52.5 & $(47.0,61.0)$ & -0.42 & $(-0.56,-0.26)$ & $<0.001$ \\
\hline Trig & 68.0 & $(51.0,101.0)$ & 83.0 & $(67.0,109.0)$ & 95.0 & $(74.0,158.0)$ & 0.28 & $(0.10-0.44)$ & 0.003 \\
\hline hs-CRP & 0.5 & $(0.3,1.5)$ & 1.0 & $(0.6,1.8)$ & 2.0 & $(1.3,4.1)$ & 0.50 & $(0.34-0.63)$ & $<0.001$ \\
\hline $\mathrm{aPC}$ & 0.5 & $(0.2,0.8)$ & 0.5 & $(0.3,1.4)$ & 0.5 & $(0.2,1.2)$ & -0.01 & $(-0.20-0.17)$ & 0.908 \\
\hline
\end{tabular}

$a P C$ activated protein $\mathrm{C}, D B P$ diastolic blood pressure, $H D L-C$ high-density lipoprotein, $h s-C R P$ high-sensitivity $\mathrm{C}$-reactive protein, $L D L-C$ lowdensity lipoprotein, SBP systolic blood pressure, TC total cholesterol, Trig triglycerides

${ }^{\text {a }}$ Spearman correlation with waist circumference analyzed as a continuous variable

${ }^{\mathrm{b}}$ Among the 118 subjects, 4 were missing a waist circumference measurement 
Table 7 Correlations between platelet parameters and components of metabolic syndrome

Values are shown as Spearman coefficients

$D B P$ diastolic blood pressure, $F B G$ fasting blood glucose, $H D L-C$ high-density lipoprotein cholesterol, $P A C 1$ integrin $\alpha_{\text {IIB }} \beta_{3}$ fibrinogen binding, $S B P$ systolic blood pressure, Trig triglycerides, $W C$ waist circumference

$* p<0.05, * * p<0.01$

\begin{tabular}{|c|c|c|c|c|c|c|}
\hline Platelet parameter & WC & HDL-C & FBG & Trig & SBP & DBP \\
\hline \multicolumn{7}{|l|}{ Platelet no. $\left(10^{3} / \mathrm{mL}\right)$} \\
\hline In citrate & $0.26^{* *}$ & -0.06 & 0.03 & 0.14 & 0.08 & 0.06 \\
\hline In EDTA & $0.22 *$ & -0.05 & 0.03 & 0.09 & 0.06 & 0.04 \\
\hline \multicolumn{7}{|l|}{ ATP (amole/platelet) } \\
\hline In citrate & -0.08 & 0.10 & $-0.30 * *$ & -0.07 & -0.13 & -0.03 \\
\hline In hirudin & -0.12 & 0.07 & $-0.26^{* *}$ & 0.01 & -0.16 & 0.03 \\
\hline \multicolumn{7}{|c|}{$\%$ suppression by $\mathrm{PGE}_{1}$ of ATP secretion } \\
\hline In citrate & 0.09 & $-0.20 *$ & 0.07 & 0.06 & 0.01 & 0.01 \\
\hline In hirudin & $0.24 *$ & $-0.23 *$ & 0.00 & 0.12 & 0.17 & 0.05 \\
\hline \multicolumn{7}{|l|}{ Basal\% expression } \\
\hline P-selectin & 0.01 & -0.02 & -0.04 & -0.04 & $-0.21^{*}$ & $-0.19^{*}$ \\
\hline PAC1 binding & 0.07 & 0.05 & 0.00 & -0.03 & -0.11 & -0.04 \\
\hline \multicolumn{7}{|l|}{$\%$ positive $\mathrm{P}$-selectin } \\
\hline ADP activation & -0.11 & 0.04 & -0.04 & -0.09 & $-0.19^{*}$ & $-0.21^{*}$ \\
\hline TRAP activation & -0.10 & 0.08 & $-0.18^{*}$ & -0.10 & -0.10 & -0.07 \\
\hline \multicolumn{7}{|l|}{$\%$ positive $\mathrm{PAC} 1$} \\
\hline ADP activation & 0.00 & -0.08 & 0.02 & 0.09 & -0.09 & 0.01 \\
\hline TRAP activation & 0.01 & 0.00 & 0.05 & 0.14 & -0.13 & -0.03 \\
\hline \multicolumn{7}{|l|}{ Microvesicles $(n=58)$} \\
\hline CD42A (platelet) & -0.02 & -0.02 & -0.04 & 0.01 & 0.00 & -0.02 \\
\hline CD14 (monocyte) & -0.09 & -0.10 & 0.07 & 0.11 & $0.31^{*}$ & 0.10 \\
\hline CD45 (leukocyte) & 0.01 & 0.06 & 0.10 & -0.18 & 0.19 & 0.14 \\
\hline CD62E (endothelium) & -0.07 & -0.13 & 0.24 & 0.25 & 0.23 & 0.06 \\
\hline ICAM-1 positive & -0.02 & -0.22 & -0.07 & $0.32 *$ & 0.14 & 0.06 \\
\hline
\end{tabular}

to the overall definition of metabolic syndrome. The novel finding of this study is that specific components for metabolic syndrome modulate the number of platelets, receptor-activated platelet secretory functions, and cellular activation of the vascular wall, which contribute to atherogenesis.

The most consistent criterion of metabolic syndrome among these recently menopausal women was waist circumference, a characteristic which showed a positive correlation with time past menopause. Central adiposity, defined by waist circumference, is associated with changes in platelet functions in other studies, but the sex and hormonal status of subjects from whom platelets were derived were not documented [27]. Consistent with other studies, the number of platelets increased with central obesity in these recently menopausal women. Cytokines, including interleukin-6 (IL-6) secreted from adipose tissue, act synergistically with other cytokines and thrombopoietin in megakaryocytopoiesis to increase platelet counts [12]. IL-6 was not measured in this study, but the IL-6 regulated acute phase hepatic protein, hs-CRP [28], increased with waist circumference. The contribution of other adipokines to these effects is of interest but beyond the scope of the present study as specific markers of adipose activation were not measured.
Basal expression of P-selectin and PAC-1 binding was $<5 \%$, suggesting that platelets were not activated by the collection procedure. However, in some women, platelets may have been partially activated in vivo prior to testing in vitro. First, both univariate and multivariate analyses identified significantly decreased P-selectin expression in basal expression and in response to ADP activation with increasing blood pressure. This relationship could reflect the in vivo depletion of the $\alpha$-granules. Measurement of soluble P-selectin, also an estimate of platelet activation, would confirm this speculation [29]. Measurement of soluble P-selectin in stored plasma samples is planned when KEEPS is closed in 2012.

In vivo activation of dense granules may occur with increases in fasting glucose as activated ATP secretion was negatively correlated with fasting glucose. Unlike other studies of individuals with increased adiposity, all values for fasting blood glucose were considered within the normal range and none of the women were diagnosed with type II diabetes, and only 13 individuals had fasting blood glucose which met the criterion for metabolic syndrome. Therefore, a major contribution of the present study is the identification of changes in platelet functions with changes in fasting blood glucose within a narrow range. 
Table 8 Univariate/multivariable analysis of platelet and microvesicle parameters with components of metabolic syndrome
Results displayed are $p$ values from univariate/multivariable regression analyses if the latter reflect a significant or borderline association (i.e., $p<0.10$. Values of $p$ in bold denote significant results $(p<0.05)$ with those italicized corresponding to negative correlations (or otherwise positive correlations)

$A D P$ adenosine diphosphate, $A T P$ adenosine triphosphate, $F B G$ fasting blood glucose, $H D L-C$ high-density lipoprotein cholesterol, ICAM-1 intercellular adhesion molecule, $P A C-1$ integrin $\alpha_{\mathrm{IIB}} \beta_{3}$ fibrinogen binding, $S B P$ systolic blood pressure, $T C$ total cholesterol, TRAP thrombin receptor agonist peptide, Trig triglycerides, $W C$ waist circumference

\begin{tabular}{|c|c|c|c|c|c|}
\hline Platelet parameter & WC & HDL-C & FBG & Trig & SBP \\
\hline \multicolumn{6}{|l|}{ Platelet number } \\
\hline In citrate & $0.010 / 0.028$ & & & & \\
\hline In EDTA & $0.014 / 0.045$ & & & & \\
\hline \multicolumn{6}{|l|}{ ATP (amol/platelet) } \\
\hline In citrate & & & $<.001 / 0.001$ & & \\
\hline In hirudin & & & $0.027 / 0.067$ & & \\
\hline \multicolumn{6}{|l|}{$\%$ suppression by $\mathrm{PGE}_{1}$} \\
\hline In citrate & & $0.020 / 0.028$ & & & \\
\hline In hirudin & & $0.037 / 0.087$ & & & \\
\hline \multicolumn{6}{|l|}{ Basal\% expression } \\
\hline P-selectin & $0.315 / 0.074$ & & & & $0.011 / 0.004$ \\
\hline \multicolumn{6}{|l|}{ PAC-1 binding } \\
\hline \multicolumn{6}{|l|}{$\%$ positive P-selectin } \\
\hline ADP activation & & & & & $0.031 / 0.055$ \\
\hline TRAP activation & & & $0.042 / 0.086$ & & \\
\hline \multicolumn{6}{|l|}{$\%$ positive $\mathrm{PAC} 1$} \\
\hline ADP activation & & & & $0.053 / \mathbf{0 . 0 1 7}$ & \\
\hline \multicolumn{6}{|l|}{ TRAP activation } \\
\hline \multicolumn{6}{|l|}{ Microvesicles } \\
\hline \multicolumn{6}{|l|}{ Platelet (CD42a) } \\
\hline Monocyte (CD14) & $0.407 / 0.023$ & & & & $0.030 / 0.005$ \\
\hline \multicolumn{6}{|l|}{ Leukocyte (CD45) } \\
\hline Endothelium (CD62E) & $0.726 / 0.067$ & & & & $0.096 / \mathbf{0 . 0 4 7}$ \\
\hline ICAM-1 positive & & & & $0.023 / 0.043$ & \\
\hline Annexin $\mathrm{V}$ positive & & & & & \\
\hline
\end{tabular}

Intrinsic cAMP activation may have been suppressed in vivo in some women as the ability for exogenous $\mathrm{PGE}_{1}$ to suppress ATP secretion increased with decreases in HDL-C. $\mathrm{PGE}_{1}$, like prostacyclin, activates adenylate cyclase to increase cAMP, which in turn blocks several steps of agonist-induced elevation of cytosolic $\mathrm{Ca}^{2+}$ (a basic mechanism of platelet activation) through specific protein kinases [30]. The correlation of $\mathrm{PGE}_{1}$ suppression with waist circumference in platelets collected in hirudin plus soybean trypsin inhibitor, but not in platelets collected in sodium citrate, might reflect the difference in the mechanisms of anticoagulation specifically related to chelation of calcium.

Although HDL-C spanned a narrow range of values, HDL-C and not LDL (data not shown) correlated with cAMP activation in platelets, supporting the conclusion that HDL-C and LDL-C affect different mechanisms of platelet integrity and activation [9]. Whether these relationships explain aspirin insensitivity in some women or whether they will be sustained by hormonal therapy remains to be determined as KEEPS proceeds.

Cell-derived microvesicles are released with cellular activation. Therefore, changes in monocyte-, endothelium-, and platelet-derived microvesicles with increases in blood pressure are consistent with in vivo activation of vascular cells and cell-cell interactions, leading to increases in CIMT and progression of plaque [31-35]. Relationships of these specific cell-derived microvesicles with specific canonical risk factors for cardiovascular disease in these recently menopausal, asymptomatic women identify potential biomarkers which may help stratify overall cardiovascular risk for early intervention. For example, endothelium-derived microvesicles increased with blood pressure, suggesting some endothelial activation which may account for the broad range of normal values of RHI [36, 37]. The relationship of triglycerides with $\mathrm{CAC}$ is consistent with a relationship to myocardial infarction reported by others [6], and the expression of fibrinogen receptors in platelets and ICAMpositive microvesicles suggests a possible mechanism which might affect calcification processes. The correlation of monocyte-derived microvesicles with waist circumference was significant only when accounting for other variables in multivariate analysis. It is unclear why this relationship is negative. Microvesicles were measured with single antibodies, and the negative correlation could reflect that monocyte-derived microvesicles, as well as endotheliumderived microvesicles, formed aggregates with each other or with other cell types and were not detected. This concept could be tested in the future by analyzing microvesicle 
populations with multiple cell-specific antibodies or using multiple cell-specific antibodies with analysis of platelet or leukocyte gates on the flow cytometer.

The ability of platelets to undergo spontaneous microaggregation, a phenomenon linked to thrombosis [38, 39], averaged $<10 \%$, which is similar to what is observed in other populations [25]. This test provides information about the sensitivity of platelets to respond to threshold stimuli in vivo. Although specific platelet functions were associated with various components of metabolic syndrome, the net effect in vivo may not have altered the overall thrombotic potential in these women within 3 years of menopause.

Plasma activated protein $\mathrm{C}$ (aPC) is an anticoagulant enzyme formed upon activation of protein $\mathrm{C}$ by the thrombin-thrombomodulin complex on the EPCR surface of endothelial cells, platelets, and monocytes. Changes in aPC can reflect either thrombin bound to thrombomodulin or the extent of endothelial protein $\mathrm{C}$ receptor activity, correlating with intravascular thrombin generation, which is known to maintain a substantial concentration in the basal steady state [40, 41]. The lack of significant association of aPC with any component of metabolic syndrome suggests a low thrombotic potential consistent with the absence of correlations between microaggregation and the various risk factors. Whether these associations will change with increased time past menopause and hormonal treatments remains to be determined.

An important advantage of this study cohort is that women were non-smokers and defined as low risk for cardiovascular disease by Framingham criteria. Therefore, the study provides insight into perhaps other phenotypic characteristics, such as those associated with metabolic syndrome, which could be incorporated into a screening tool to better define cardiovascular risk in women at the menopausal transition [42].

One potential criticism of the study is that significant correlations with multiple comparisons occurred by chance. Based on the null distribution of $p$ values, of the 120 correlations tested, about four to six correlations nominally significant at the 0.05 level would have occurred by chance. Since there were 14 such correlations, more than double the expected chance finding, and because there were relationships consistent between single parameters tested in platelets collected in different anticoagulants, it is unlikely that chance alone explains these associations. Furthermore, the number of results nominally significant at the 0.01 level was 3 compared with the expected number of 1 . Thus, it is likely that at least some of these findings were not type I errors, particularly given the fact that the direction of the effects corresponded with prior expectations.

In conclusion, in recently menopausal women, individual components of metabolic syndrome affect specific platelet functions and production of cell-derived microvesicles. Of those components, waist circumference, fasting blood glucose, blood pressure, and HDL-C had the strongest independent effects. Thus, these uniquely sensitive yet detectable variations in platelet activities may precede adverse changes in vascular anatomy as some correlated with thickening in the carotid artery, a measure of early atherosclerosis [43-45]. Since there is an established association of menopause with development of the metabolic syndrome, its modulation using hormonal therapy at the time of onset may provide an ideal opportunity for intervention to limit the development and progression of atherosclerotic lesion formation [22, 46, 47]. Indeed, KEEPS is designed to study the effects of hormone therapy on atherosclerosis and a variety of other outcomes when administered to women who have recently become menopausal [21, 48].

As oral estrogen preparations may increase thrombotic risk [49-53], it remains a challenge to identify those parameters in an individual woman that may help define thrombotic risk. KEEPS participants are randomized to transdermal, oral, or no estrogen therapy, and follow-up over 4 years will enable outcomes analysis of the effect of hormone therapy and its optimal delivery route on cardiovascular and atherothrombotic risk while elucidating how these parameters relate to quantifiable function of the endothelium by arterial tonometry and assessment of vascular anatomy by CAC and CIMT. Thus, we await future observations regarding the potential impact of hormonal modulation on these platelet functions and cell-derived microvesicles as they interplay with components of the metabolic syndrome in order to provide mechanistic insights into the endothelial substrate response predisposing to atherogenesis during the transition to and following menopause.

Acknowledgments This work was supported by grants from the Aurora Foundation to the Kronos Longevity Research Institute, NIH HL90639, 1UL1 RR024150 ${ }^{1}$, American Heart Association-Scientist Development Grant, AHA 08-30503Z, and the Mayo Foundation. The authors thank the dedicated volunteers participating in this study and co-workers who made this possible, including Phillip A. Araoz, MD, Rebecca Beck, RN, Teresa G. Zais, and the staff in the Women's Health Clinic.

Open Access This article is distributed under the terms of the Creative Commons Attribution Noncommercial License which permits any noncommercial use, distribution, and reproduction in any medium, provided the original author(s) and source are credited.

\footnotetext{
${ }^{1}$ From the National Center for Research Resources (NCRR), a component of the National Institutes of Health (NIH), and the NIH Roadmap for Medical Research. Contents of this paper are solely the responsibility of the authors and do not necessarily represent the official view of NCRR or NIH. Information on NCRR is available at http://www.ncrr.nih.gov/. Information on Reengineering the Clinical Research enterprise can be obtained from http://nihroadmap.nih.gov.
} 


\section{References}

1. Grundy, S. M., Cleeman, J. I., Daniels, S. R., Donato, K. A., Eckel, R. H., Franklin, B. A., et al. (2005). Diagnosis and management of the metabolic syndrome: An American Heart Association/National Heart, Lung, and Blood Institute Scientific Statement. Circulation, 112, 2735-2752.

2. Regitz-Zagrosek, V., Lehmkuhl, E., \& Weickert, M. O. (2006). Gender differences in the metabolic syndrome and their role for cardiovascular disease. Clin Res Cardiol, 95, 136-147.

3. Salpeter, S. R., Walsh, J. M., Ormiston, T. M., Greyber, E., Buckley, N. S., \& Salpeter, E. E. (2006). Meta-analysis: Effect of hormone-replacement therapy on components of the metabolic syndrome in postmenopausal women. Diabetes, Obesity and Metabolism, 8, 538-554.

4. Executive Summary of the Third Report of The National Cholesterol Education Program (NCEP) Expert Panel on Detection, Evaluation, And Treatment of High Blood Cholesterol In Adults (Adult Treatment Panel III) (2001). JAMA, 285, 2486-2497

5. Alberti, K. G., Zimmet, P., \& Shaw, J. (2006). Metabolic syndrome-A new world-wide definition. A Consensus Statement from the International Diabetes Federation. Diabet Med, 23, 469480. doi:10.1111/j.1464-5491.2006.01858.x.

6. Ninomiya, J. K., L'Italien, G., Criqui, M. H., Whyte, J. L., Gamst, A., \& Chen, R. S. (2004). Association of the metabolic syndrome with history of myocardial infarction and stroke in the Third National Health and Nutrition Examination Survey. Circulation, 109, 42-46. doi:10.1161/01.CIR.0000108926.04022.0C.

7. Kurrelmeyer, K., Becker, L., Becker, D., Yanek, L., GoldschmidtClermont, P., \& Bray, P. F. (2003). Platelet hyperreactivity in women from families with premature atherosclerosis. $J$ Am Med Womens Assoc, 58, 272-277.

8. Ross, R. (1995). Cell biology of atherosclerosis. Annu Rev Physiol, 57, 791-804.

9. Ferroni, P., Basili, S., \& Davi, G. (2003). Platelet activation, inflammatory mediators and hypercholesterolemia. Curr Vasc Pharmacol, 1, 157-169.

10. Calverley, D. C., Brass, E., Hacker, M. R., Tsao-Wei, D. D., Espina, B. M., Pullarkat, V. A., et al. (2002). Potential role of platelet FcyRIIA in collagen-mediated platelet activation associated with atherothrombosis. Atherosclerosis, 164, 261-267.

11. Miller, V. M., Jayachandran, M., Hashimoto, K., Heit, J. A., \& Owen, W. G. (2008). Estrogen, inflammation, and platelet phenotype. Gender Medicine, 5, S91-S102.

12. Baatout, S. (1999). Interleukin-6 and megakaryocytopoiesis: An update. Ann Hematol, 73, 157-162.

13. Cocucci, E., Racchetti, G., \& Meldolesi, J. (2009). Shedding microvesicles: Artefacts no more. Trends Cell Biol, 19, 43-51.

14. Piccin, A., Murphy, W. G., \& Smith, O. P. (2007). Circulating microparticles: Pathophysiology and clinical implications. Blood Rev, 21, 157-171.

15. Jayachandran, M., Litwiller, R. D., Owen, W. G., Heit, J. A., Behrenbeck, T. R., Mulvagh, S. L., et al. (2008). Characterization of blood borne microparticles as markers of premature coronary calcification in newly menopausal women. Am J Physiol Heart Circ Physiol, 295, 931-938. doi:10.1152/ajpheart.00193.2008.

16. Helal O, Defoort C, Robert S, Marin C, Lesavre N, LopezMiranda J, Riserus U, Basu S, Lovegrove J, McMonagle J, Roche HM, Dignat-George F, Lairon D. (2011). Increased levels of microparticles originating from endothelial cells, platelets and erythrocytes in subjects with metabolic syndrome: Relationship with oxidative stress. Nutrition, Metabolism, and Cardiovascular Diseases. doi:10.1016/j.numecd.2010.01.004.

17. Agouni, A., Lagrue-Lak-Hal, A. H., Ducluzeau, P. H., Mostefai, H. A., Draunet-Busson, C., Leftheriotis, G., et al. (2008).
Endothelial dysfunction caused by circulating microparticles from patients with metabolic syndrome. Am J Pathol, 173, 1210-1219.

18. Miller, V. M., Black, D. M., Brinton, E. A., Budoff, M. J., Cedars, M. I., Hodis, H. N., et al. (2009). Using basic science to design a clinical trial: baseline characteristics of women enrolled in the Kronos Early Estrogen Prevention Study (KEEPS). J Cardiovasc Transl Res, 2, 228-239.

19. Hodis, H. N., \& Mack, W. J. (2008). Postmenopausal hormone therapy and cardiovascular disease in perspective. Clin Obstet Gynecol, 51, 564-580.

20. Matthews, K. A., Crawford, S. L., Chae, C. U., Everson-Rose, S. A., Sowers, M. F., Sternfeld, B., et al. (2009). Are changes in cardiovascular disease risk factors in midlife women due to chronological aging or to the menopausal transition? J Am Coll Cardiol, 54, 2366-2373. doi:10.1016/j.jacc.2009.10.009.

21. Harman, S. M., Brinton, E. A., Cedars, M., Lobo, R., Manson, J. E., Merriam, G. R., et al. (2005). KEEPS: The Kronos Early Estrogen Prevention Study. Climacteric, 8, 3-12.

22. Hodis, H., Mack, W., Lobo, R., Shoupe, D., Sevanian, A., Mahrer, P., et al. (2001). Estrogen in the prevention of atherosclerosis. A randomized, double-blind, placebo-controlled trial. Ann Intern Med, 135, 939-953.

23. Mulvagh, S. L., Behrenbeck, T., Lahr, B. A., Bailey, K. R., Zais, T. G., Araoz, P. A., et al. (2010). Endothelial function and cardiovascular risk stratification in menopausal women. Climacteric, 13, 45-54.

24. McBane, R. D., 2nd, Karnicki, K., Tahirkheli, N., Miller, R. S., \& Owen, W. G. (2003). Platelet characteristics associated with coronary artery disease. J Thromb Haemost, 1, 1296-1303.

25. Jimenez, T. M., Patel, S. B., Pineda, A. A., Tefferi, A., \& Owen, W. G. (2003). Factors that influence platelet recovery after transfusion: Resolving donor quality from $\mathrm{ABO}$ compatibility. Transfusion (Paris), 43, 328-334.

26. Smith, R. D., \& Owen, W. G. (1999). Platelet responses to compound interactions with thrombin. Biochemistry (Mosc), 38, 8936-8947.

27. Anfossi, G., Russo, I., \& Traovati, M. (2009). Platelet dysfunction in central obesity. Nutrition, Metabolism \& Cardiovascular Disease, 19, 440-449.

28. Yudkin, J. S., Stehouwer, C. D. A., Emeis, J. J., \& Coppack, S. W. (1999). C-reactive protein in healthy subjects: Association with obestiy, insulin resistance and endothelial dysfunction. A potential role for cytokines originating from adipose tissue? Arterioscler Thromb Vasc Biol, 19, 972-978.

29. Ziccardi, P., Nappo, F., Giugliano, G., Esposito, K., Marfella, R., Cioffi, M., et al. (2002). Reduction of inflammatory cytokine concentrations and improvement of endothelial functions in obese women after weight loss over one year. Circulation, 105, 804-809.

30. Rink, T. G., \& Sage, S. O. (1990). Calcium signaling in human platelets. Ann Review of Physiology, 52, 431-449.

31. Mack, W. J., Slater, C. C., Xiang, M., Shoupe, D., Lobo, R. A., \& Hodis, H. N. (2004). Elevated subclinical atherosclerosis associated with oophorectomy is related to time since menopause rather than type of menopause. Fertil Steril, 82, 391-397.

32. Steiner, A., Hodis, H. N., Lobo, R. A., Shoupe, D., Xiang, M., \& Mack, W. J. (2005). Postmenopausal oral estrogen therapy and blood pressure in normotensive and hypertensive subjects: The Estrogen in the Prevention of Atherosclerosis Trial. Menopause, 12, 728-733.

33. Kaplan, R. C., Sinclair, E., Landay, A. L., Lurain, N., Sharrett, A. R., Gange, S. J., et al. (2011). T cell activation and senescence predict subclinical carotid artery disease in HIV-infected women. $J$ Infect Dis, 203, 452-463. doi:10.1093/infdis/jiq071.

34. Hwang, J., Hodis, H. N., Hsiai, T. K., Asatryan, L., \& Sevanian, A. (2006). Role of annexin II in estrogen-induced macrophage matrix metalloproteinase- 9 activity: The modulating effect of statins. Atherosclerosis, 189, 76-82. doi:10.1016/j.atherosclerosis.2005.11.026.

35. Leroyer, A. S., Isobe, H., Leseche, G., Castier, Y., Wassef, M., Mallat, Z., et al. (2007). Cellular origins and thrombogenic 
activity of microparticles isolated from human atherosclerotic plaques. J Am Coll Cardiol, 49, 772-777.

36. Bonetti, P. O., Pumper, G. M., Higano, S. T., Holmes, D. R., Jr., Kuvin, J. T., \& Lerman, A. (2004). Noninvasive identification of patients with early coronary atherosclerosis by assessment of digital reactive hyperemia. $J$ Am Coll Cardiol, 44, 2137-2141.

37. Hamburg, N. M., Keyes, M. J., Larson, M. G., Vasan, R. S., Schnabel, R., Pryde, M. M., et al. (2008). Cross-sectional relations of digital vascular function to cardiovascular risk factors in the Framingham Heart Study. Circulation, 117, 2467-2474.

38. Splawinska, B., Furmaga, W., Kuzniar, J., Stawiarski, M., Pikor, I., Szmigiel, Z., et al. (1987). Formation of prostacyclin-sensitive platelet aggregates in human whole blood in vitro. Part II. The occurrence of the phenomenon in males suffering from acute myocardial infarction. Scand J Clin Lab Invest, 47, 125-130.

39. Wu, K. K., \& Hoak, J. C. (1976). Spontaneous platelet aggregation in arterial insufficiency: Mechanisms and implications. Thromb Haemost, 35, 702-711.

40. Zoldhelyi, P., Chesebro, J. H., \& Owen, W. G. (1993). Hirudin as a molecular probe for thrombin in vitro and during systemic coagulation in the pig. Proc Natl Acad Sci USA, 90, 1819-1823.

41. Zoldhelyi, P., Bichler, J., Owen, W. G., Grill, D. E., Fuster, V., Mruk, J. S., et al. (1994). Persistent thrombin generation in humans during specific thrombin inhibition with hirudin. Circulation, 90, 2671-2678.

42. Mosca, L., Benjamin, E. J., Berra, K., Bezanson, J. L., Dolor, R. J., Lloyd-Jones, D. M., et al. (2011). Effectiveness-based guidelines for the prevention of cardiovascular disease in women - 2011 update: A guideline from the American Heart Association. Circulation, 123, 1243-1262. doi:10.1161/CIR.0b013e31820faaf8.

43. Hodis, H. N., Mack, W. J., LaBree, L., Selzer, R. H., Liu, C. R., Liu, C. H., et al. (1998). The role of carotid arterial intima-media thickness in predicting clinical coronary events. Ann Intern Med, $128,262-269$.

44. Hodis, H. N., \& Mack, W. J. (2002). Atherosclerosis imaging methods: Assessing cardiovascular disease and evaluating the role of estrogen in the prevention of atherosclerosis. Am J Cardiol, 889, 19E-27E.

45. Blankenhorn, D. H., \& Hodis, H. N. (1994). Duff Memorial Lecture: Arterial imaging and atherosclerosis reversal. Arterioscler Thromb, 14, 177-192.

46. Karim, R., Mack, W. J., Lobo, R. A., Hwang, J., Liu, C. R., Liu, C. H., et al. (2005). Determinants of the effect of estrogen on the progression of subclinical atherosclerosis: Estrogen in the Prevention of Atherosclerosis Trial. Menopause, 12, 366-373.

47. Hodis, H. N., Mack, W. J., Azen, S. P., Lobo, R. A., Shoupe, D., Mahrer, P. R., et al. (2003). Hormone therapy and the progression of coronary-artery atherosclerosis in postmenopausal women. New Engl J Med, 349, 535-545.

48. Clarkson, T. B. (2007). Estrogen effects on arteries vary with stage of reproductive life and extent of subclinical atherosclerosis progression. Menopause, 14, 373-384.

49. Luyer, M. D. P., Khosla, S., Owen, W. G., \& Miller, V. M. (2000). Prospective randomized study of effects of unopposed estrogen replacement therapy on markers of coagulation and inflammation in postmenopausal women. $J$ Clin Endocrinol Metab, 86, 3629-3634.

50. Scarabin, P. Y., Alhenc-Gelas, M., Plu-Bureau, G., Taisne, P., Agher, R., \& Aiach, M. (1997). Effects of oral and transdermal estrogen/progesterone regimens on blood coagulation and fibrinolysis in postmenopausal women: A randomized controlled trial. Arterioscler Thromb Vasc Biol, 17, 3071-3078.

51. Scarabin, P. Y., Oger, E., \& Plu-Bureau, G. (2003). Differential association of oral and transdermal oestrogen-replacement therapy with venous thromboembolism risk. The Lancet, 362, 428-432.

52. Lacut, K., Oger, E., Le Gal, G., Blouch, M.-T., Abgrall, J.-F., Kerlan, V., et al. (2003). Differential effects of oral and transdermal postmenopausal estrogen replacement therapies on C-reactive protein. Thromb Haemost, 90, 124-131.

53. Canonico, M., Oger, E., Plu-Bureau, G., Conard, J., Meyer, G., Levesque, H., et al. (2007). Hormone therapy and venous thromboembolism among postmenopausal women. Circulation, 115, 840-845. 